Received: 17 November 2018

Accepted: 12 February 2018

Online: 23 February 2018

Authors:

A. Indumathi $₫$

E.S College of Nursing, Villupuram

Tamilnadu, India

$\bigotimes$ indu.mahin@gmail.com

Emer Life Sci Res (2018) 4(1): 11-14

E-ISSN: 2395-6658

P-ISSN: 2395-664X

DOI: https://doi.org/10.31783/elsr.2018.411114

\section{Research Article \\ Effectiveness of ice massage in reduction of labor pain during first stage of labor among primigravida mothers}

\author{
A. Indumathi
}

\begin{abstract}
Labor is a stressful experience that has pain, fatigue, fear and negative moods reaching high levels as labor progresses. The objective of this study was to assess the effectiveness of ice massage in reduction of labor pain between control and experimental group. Quantitative research approach and Quasi experimental after research only design was adopted for this study. Sixty Primigravida mothers at first stage of labor were divided as 30 each in both the experimental and control group. Visual analogue scale was utilized to assess the labor pain. Experimental group participants received ice massage at energy meridian point that is known as Large intestine 4(LI 4) for subsequent 4 uterine contractions or for 20 minutes. This intervention was not followed in control group. The collected data were examined by descriptive and inferential statistics. Results of the study revealed that $23.3 \%$ of mothers had moderate pain and $76.67 \%$ had severe pain in control group and in experimental group, $3.33 \%$ of mothers had mild pain, $83.33 \%$ had moderate pain and $13.33 \%$ had severe pain. A significant difference at the level of $p<0.05$ was found between the experimental and control group on labor pain. This experiment also revealed that there was significant association between the pain score in experimental group and their selected demographic variables such as type of family, residence and occupation. It was concluded that the ice massage at energy meridian point (LI 4) was the effective method to reduce labor pain during the first stage of labor.
\end{abstract}

Keywords energy meridian point, ice massage, labor pain, primigravida mothers

\section{Introduction}

Birth has been potentially empowering, possibly traumatic, and in many instances, life transforming. Interpretations of performance during childbirth can serve as indicators of perceived capabilities in the mothering role [1]. Chapman described labor pain as stimuli of receptive neurons arising from contractions of the uterine muscles, which are referred as the visceral, pelvic, and lumbo- scral areas. The pain and discomfort of labor has two origins; visceral and somatic [2]. Right from the beginning of life, women are supposed to undergo labor pain, which is undoubtedly one of the most painful conditions. However, modern medicine has been trying to put an end to this painful experience. Nowadays, we can witness an enormous growth in the field of complementary alternative medicine (CAM) [3]. Due to its growth, various alternative methods are being used to relieve pain during labor. The advancement of technological improvements has proved the efficacy 
of life saving procedure in obstetrics. The comfort measures like ice massage at energy meridian point called large intestine 4 pathway moves from the tip of the fore finger to the face and then it encircles the teeth. Later, it bifurcates at the shoulder and moves downward wrapping around the entire colon [4]. During pregnancy term, the colon practically encircles the upper portion of the uterus. The efficacy of ice massage at energy meridian point works under the mechanism of gate control theory [5].

Labor pain is almost universal, experienced by nearly $95 \%$ of women [6]. Childbirth pain is one of the most severe types of pain, woman may experience in her lifetime. Many women experience intense pain in labor, which may increase in severity and duration over time. It has a high degree of variability among individuals and at different points in labor. In a study of primiparous women during the first stage of labor, $60 \%$ women described the pain during the first stage of labor as unbearable, intolerable, extremely severe and excruciating. However, they described the variation in the pain during the first and second stages. In first stage, the labor pain was described like cramping, pulling, aching, heavy, sharp, stabbing, throbbing (sensory), unbearable, agonizing, overwhelming and engulfing (effective); but in second stage, it exerts painful pressure, burning, ripping, tearing, piercing, explosive, (sensory) exhausting, exciting, horrible, terrifying (effective) [7]. To escape from these changes in physical and mental temperament, most women are opting for caesarean nowadays.

The Indian Council of Medical Research (ICMR) conducted a study in 2009 stateing that in India nearly 27 million women give birth every year. Among them, 25\% of women opt for caesarean section and $18 \%$ of them electively go for it. The reason behind this is that they do not want to experience labor pain [8]. Caesarean delivery give relief from the pain at the time of delivery, but the problems behind it are obvious. There is infection, heavy blood loss, a blood clot in the legs or lungs, bowel problems, injury to other organs (bladder), permanent scar, open of the incision scar during later pregnancy etc., although it is very rare sometimes maternal death also occurs (about 2 in 100,000 cesareans result in maternal death) [9].

\section{Methodology}

Quantitative approach and Quasi experimental after research only design was adopted for this study. The study was conducted in infant Jesus hospitals, Madurai district, Tamilnadu, India. The setting was selected on the basic feasibility in terms of availability of adequate patients on cooperation extended by the authority. The patients comprised of primigravida mothers in first stage of labor who fulfill the inclusion criteria. Sixty primigravida mothers at first stage of labor were divided as 30 mothers in the experimental group and 30 in control group by adopting purposive sampling technique. The tool consisted of three sections. Section - I: It dealt with the demographic performance of the mothers like age, educational status, religion, residence, type of family, occupation. Section - II: An observational checklist was used to select the Primigravida mothers. Section - III: A modified visual analogue scale was used to assess the pain level.

\section{Method of data collection}

Data collection was done within the given period of 6 weeks. The study was conducted on 60 primigravida mothers who met the inclusion criteria, among them 30 mothers were taken as experimental group and 30 mothers were considered as control group.

Table 1. Percentage distribution on level of pain in control and experimental group

\begin{tabular}{|l|l|c|c|c|}
\hline \multirow{2}{*}{ S.no } & \multirow{2}{*}{ Group } & \multicolumn{3}{|c|}{ Level of pain } \\
\cline { 3 - 5 } & & Mild & Moderate & Severe \\
\hline \multirow{2}{*}{1.} & Control Group & - & 7 & 23 \\
& & $(0)$ & $(23.33 \%)$ & $(76.67 \%)$ \\
\hline 2. & Experimental Group & 1 & 25 & 4 \\
\hline
\end{tabular}


Prior to data collection procedure, the investigator obtained formal permission. Initially, the investigator selected the primigravida mothers to apply ice massage based on the observational checklist and inclusion criteria. The samples were selected by using purposive sampling.

Every day, investigator observed each patient, explained them about the nature of the study, its purpose, got oral consent from the mothers to participate in this study and had given assurance to keep the information confidential. Ice massage was given at energy meridian point known as large intestine 4 (LI 4) only to experimental group mothers during uterine contraction. The ice massage was stopped when the contractions ended and started when the next contraction began. Like this, the investigator applied ice massage at energy meridian points for subsequent 3 or 4 contractions or for 20 minutes in active phase. After delivery, posttest was conducted to both the experimental and control group mothers by administered modified visual analogue scale and the pain level was assessed. Each day 1-2 mothers were assessed.

\section{Results}

Table1 reveals that 7 (23.33\%) mothers had moderate pain and 23 (76.67\%) mothers had severe pain in control group, but in experimental group 1 (3.33\%) mother had mild pain, 25 (83.33\%) mothers had moderate pain and only $4(13.33 \%)$ mothers had severe pain.

The mean value of control and experimental group was 8.43 and 5.13, respectively; and the calculated ' $t$ ' value was 11.22 at $5 \%$ level of significance. The calculated ' $t$ ' value was more than the table value (2.002). This indicates that there was a significant difference between the control and experimental group pain score. It was concluded that ice massage is effective intervention in reduction of labor pain during the first stage of labor among primigravid mothers. The present study findings revealed that in experimental group there was a significant association between the pain level score and selected demographic variables such as residence, type of family, and occupation at $\mathrm{P}<0.05 \%$ level.

Table 2. Comparison on level of pain in control and experimental group

\begin{tabular}{|l|c|c|c|c|c|}
\hline S.no & Characteristics & Mean score & Standard deviation & $\begin{array}{c}\text { Calculated ' } \mathbf{t} \text { ' } \\
\text { Value }\end{array}$ & $\begin{array}{c}\text { Tabulated ' } \mathbf{t} \text { ' } \\
\text { Value }\end{array}$ \\
\hline 1. & Control group & 8.43 & 1.082 & 11.25 & \\
\hline 2. & Experimental group & 5.13 & 1.358 & $(0.296)$ & 2.002 \\
\hline
\end{tabular}

\section{Discussion}

Out of 30 samples in control group, none of the mothers had mild pain, 7 (23.33\%) mothers had moderate pain and $23(76.67 \%)$ mothers had severe pain; but in experimental group out of 30 samples, 1(3.33\%) mother had mild pain, 25(83.33\%) mothers had moderate pain and only $4(13.33 \%)$ mothers had severe pain. The table 2 reveals that there is difference in the mean score and standard deviation of control and experimental group and also proved that the calculated ' $t$ ' value was more than the tabulated ' $t$ ' value.

This study findings were consistent with the another study conducted by Mercia Rekha [10], on the effectiveness of ice massage for the reduction of labor pain. Their study findings showed that mean and standard deviation of control group were 5.3 and 1.922, respectively and mean and standard deviation of experimental group were 2.1 and 1.922 , respectively. Calculated t valve was 6,806 which is highly significant at $\mathrm{p}<0.05$ level. It revealed that there was significant difference in control and experimental group. The present study findings also revealed that only in experimental group, there was a significant association between the pain level score and selected demographic variables such as residence, type of family, and occupation at $\mathrm{P}<0.05 \%$ level. 


\section{Conclusion}

The findings of the present study revealed that the ice massage on LI 4 is one of the safe noninvasive and non-pharmacological methods of reducing labor pain. The study also showed that the mothers from urban residence, mothers living in nuclear family and the mothers who are homemakers had better coping up capacity with pain during the time of labor. This study proved that the ice Massage at energy meridian point (LI 4) will help to reduce the labor pain.

\section{Acknowledgements}

The author would like to express the special thanks to the guide Dr. Shabera Banu M.Sc (N),Phd, extend sincere thanks to Dr. Indra Raja D.G.O and Dr. Chalice Raja, M.S.,(O\&G) for giving permission to conduct the study in their Infant Jesus Maternity clinic as well as for their necessary guidance and valuable recommendations. The author extends sincere gratitude to mothers who enthusiastically participated in the study and also the nurses working in Infant Jesus Maternity clinic for their cooperation.

\section{Conflict of interest}

None declared.

\section{References}

[1] L. K. Low, K. Martin, C. Sampselle, B. Guthrie, D. Oakley (2003). Adolescents' Experiences of childbirth: Contrasts with Adults. J. Midwifery Women's Health, 48: 192-198.

[2] N. K. Lowe (2002). The nature of labor pain. Am. J. Obstet. Gynecol., 186: S16-24.

[3] A. D. Allaire (2001). Complementary and alternative medicine in the labor and delivery suite. Clin. Obstet. Gynecol., 44: 681-691.

[4] B. L. Waters and J. Raisler (2003). Ice massage for the reduction of labor pain. J. Midwifery Women's Health.; 48: 317-321.

[5] R. Melzack and P. D. Wall (1965). Pain mechanisms: a new theory. Science; 150: 971-979.

[6] K. Edmonds(Ed.) (2011). Dewhurst'sTextbook of Obstetrics and Gynaecology. John Wiley and Sons, Ltd.

[7] K. R. Simpson (2013). AWHONN's Perinatal nursing. Lippincott Williams \& Wilkins.

[8] Delivery us from pain. Published an article in India today. (2009). http://m.indiatoday.in/story/Deliver+us+from + pain/1/55936.html.

[9] Labor and Delivery: complications of cesarean section - healthline. https:// www.webmd.com+baby+cesarean delivery.

[10] Mercia Rekha D’Souza (2010). A window for health in action. Journal of Nightingale nursing times. 5: No. 12 . 